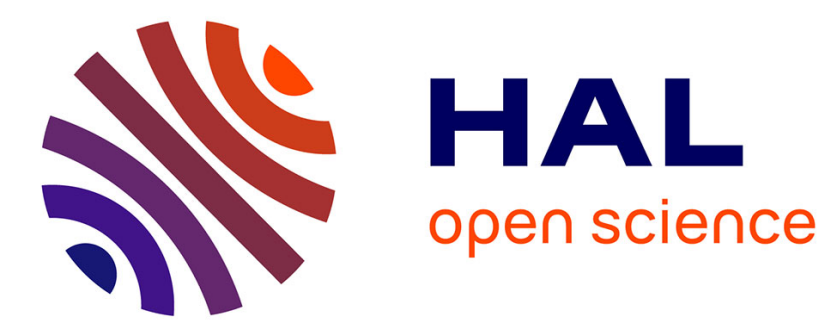

\title{
AN ULTRASONIC STUDY OF THE RATE CONTROLLING MECHANISM OF DISLOCATION MOTION AT HIGH RATES OF STRAIN
}

J. Shioiri, K. Satoh

\section{> To cite this version:}

J. Shioiri, K. Satoh. AN ULTRASONIC STUDY OF THE RATE CONTROLLING MECHANISM OF DISLOCATION MOTION AT HIGH RATES OF STRAIN. Journal de Physique Colloques, 1985, 46 (C5), pp.C5-3-C5-10. 10.1051/jphyscol:1985501 . jpa-00224730

HAL Id: jpa-00224730

https://hal.science/jpa-00224730

Submitted on 1 Jan 1985

HAL is a multi-disciplinary open access archive for the deposit and dissemination of scientific research documents, whether they are published or not. The documents may come from teaching and research institutions in France or abroad, or from public or private research centers.
L'archive ouverte pluridisciplinaire HAL, est destinée au dépôt et à la diffusion de documents scientifiques de niveau recherche, publiés ou non, émanant des établissements d'enseignement et de recherche français ou étrangers, des laboratoires publics ou privés. 


\title{
AN ULTRASONIC STUDY OF THE RATE CONTROLLING MECHANISM OF DISLOCATION MOTION AT HIGH RATES OF STRAIN
}

\author{
J. Shioiri and $\mathrm{K}$. Satoh ${ }^{+}$ \\ Department of Mechanical Engineering, College of Engineering, Hosei \\ University, Koganei-shi, Tokyo 184, Japan \\ tDepartment of Aeronautics, Faculty of Engineering, University of Tokyo, \\ Bunkyo-ku, Tokyo 113, Japan
}

\begin{abstract}
Résumé - L'atténuation des ultrasons au cours de la déformation dynamique d'échantillons a été mesurée dans le cas de 1'aluminium de haute pureté, pour des vitesses de déformation atteignant $8000 / \mathrm{sec}$ et des températures s'étendant jusqu'à $500 \mathrm{~K}$. Les résultats sont analysés en vue d'étudier le comportement des dislocations. On a particulièrement étudié la transition des mécanismes contrôlant les déplacements de dislocations, depuis l'activation thermique jusqu'au frottement visqueux. On trouve que cette transition apparâ̂t progressivement dans la gamme de vitesses de déformation $10^{3}-10^{4} / \mathrm{sec}$.

Abstract - The ultrasonic attenuation in specimens undergoing dynamic plastic deformation was measured for polycrystalline high purity aluminium over the strain rate range up to $8000 / \mathrm{sec}$ and at temperatures ranging up to $500 \mathrm{~K}$. The results were analysed to obtain information on the behaviour of dislocations at high rates of strain. Emphasis was put on the transition in the rate controlling mechanism of the dislocation motion from the thermal activation to the viscous drag. It was found that the transition occurs gradually over the strain rate range from $10^{3}$ to $10^{4} / \mathrm{sec}$.
\end{abstract}

\section{I - INTRODUCTION}

The mechanical properties of metallic materials at high rates of strain have been extensively studied during the last three decades. At present, one of the matters of concern of the scientists and engineers in this field is the problem of the transition in the rate controlling mechanism of the dislocation motion, from the thermal activation in the lower strain rate side to the viscous drag in the higher strain rate side, which is expected to occur at a very high rate of strain. As an evidence of the above transition, abrupt changes in the strain rate sensitivity of the flow stress observed at strain rates around $10^{4} / \mathrm{sec}$ have been reported by many investigators as reviewed, for example, by Campbel1 /1/. However, Lindholm $/ 2,3$ / raised a question as to the applicability of the conventional split Hopkinson pressure bar technique at such high rates of strain. In fact, refined experiments by him showed no evidence of such transition in the rate controlling mechanism. For aluminium he observed a change in the strain rate sensitivity of the flow stress, but, taking account of the temperature dependency of the flow stress measured simultaneously, he attributed the change to a transition between two thermal activation mechanisms. At this stage, therefore, in order to clarify the transition problem and, further, to derive constitutive equations for a wide range of strain rate which includes the expected transition region, extensive experimental knowledge on the behaviour of dislocations at high rates of strain is required.

Experimental method of investigating the behaviour of dislocations under dynamic plastic deformation have been confined mostly to the measurement of the flow stress under appropriate loading conditions or to the electron microscopy of the disloca- 
tion configurations after deformation. In order to develop a more direct method, the present authors tried time-resolved measurements of the attenuation and velocity of the ultrasonic wave in specimens undergoing dynamic plastic deformation $/ 4,5,6 /$. In the latest work $/ 6 /$, the strain rate range, in which the ultrasonic measurement was possible, was extended up to $8000 / \mathrm{sec}$, where the effect of the viscous drag against the dislocation motion is expected to become explicit in the flow stress.

The viscous drag due to the phonon interaction has a temperature dependency different from the thermal activation process. In the present work, therefore, in order to obtain more detailed information on the transition in the rate controlling mechanism, the ultrasonic measurements were made for high purity polycrystalline aluminium at temperatures up to $500 \mathrm{~K}$. Putting emphasis upon the transition in the rate controlling mechanism of the dislocation motion, the ultrasonic data were analysed by using the results of the theoretical analysis presented in the previous paper 16/, which treated the effect of the dislocations under glide motion upon the attenuation and velocity of the superimposed ultrasonic wave. The above theoretical analysis covered both the thermal activation-controlled flow and viscous drag-controlled flow ranges.

\section{II - MODEL FOR DISLOCATION KINETICS AT HIGH RATES OF STRAIN}

In this paper, a simplified model for the kinetics of dislocations at high rates of strain is used to consider the transition in the rate controlling mechanism of the dislocation motion on the basis of the results of the ultrasonic measurements. Since this type of model has already appeared in 1iteratures many times $/ 6,7,8,9 /$, in the following its outline necessary for the description of the present paper will be brief1y introduced.

The intrinsic drag against dislocation motion in fcc metals such as aluminium and copper is given in the following linear viscous form:

$$
\tau b=\mathrm{Bv}
$$

where $\tau$ is the resolved shear stress, $b$ is the Burgers vector, $B$ is the damping constant, $v$ is the dislocation velocity $/ 10 /$. However, this drag, caused by the interaction between the phonon and dislocations, is usually very small and, except at very high strain rates, the dominant rate controlling mechanism of the dislocation motion is the point obstacles to be overcome with the aid of the thermal activation. In pure metals, the dominant point obstacles are the forest dislocations. As is shown schematically in Fig. 1(a), the mobile dislocation segments move repeating the therma11y assisted cutting of the forest dislocations and the viscous dragcontrolled jump motion alternately. Since the thermally assisted cutting requires a waiting time, the motion of the mobile segments in the above process will be "jerky". By simplifying the unit motion of the segment as shown in Fig. 1(b), the rate of shear strain due to the above jerky motion of the dislocation segements, $\dot{\gamma}_{d}$, is given by

$$
\dot{\gamma}_{d}=N L^{2} b /\left(t_{t}+t_{v}\right)=N L^{2} b /\left\{\nu^{-1} \exp [(U-\alpha \tau) / k T]+L B / \tau b\right\}
$$

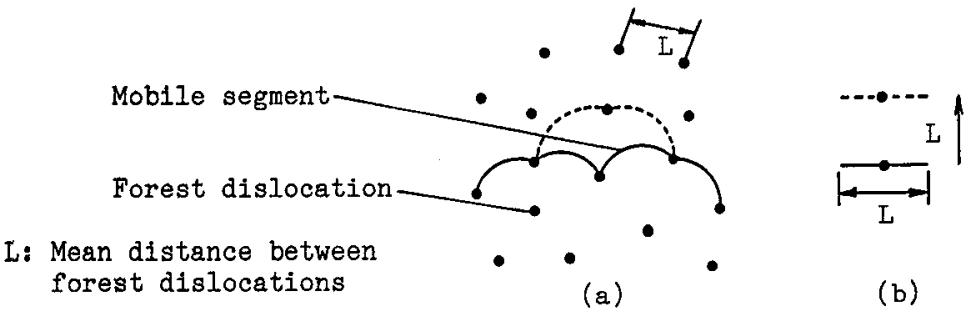

Fig. 1 - Kinetic model for dislocation segment motion under dynamic deformation. 
where $t_{t}$ is the waiting time for the thermally assisted cutting, $t_{v}$ is the time required by one jump motion under the control of the viscous drag, $N$ is the number of the mobile segments per unit volume, $L$ is the mean distance between the forest dislocations, $U$ and $\alpha$ are the activation energy and the activation volume of the cutting, $\nu$ is the frequency factor, $k$ is the Boltzmann constant, and $T$ is the absolute temperature. The simplest expression of $\alpha$ is

$$
\alpha=\mathrm{Lb}^{2} \text {. }
$$

Equation (2) can cover the thermal activation flow range, the transition range and the viscous flow range. At lower stresses where $t_{t}>t_{v}, E q$. (2) can be approximated as

$$
\dot{\gamma}_{\mathrm{d}}=\mathrm{NL}^{2} \mathrm{b \nu} \exp [-(\mathrm{U}-\alpha \tau) / \mathrm{kT}] .
$$

This is the same as the expression given by Seeger /11/ for the thermal activation flow in which the flow stress depends linearly upon the logarithm of the strain

rate. At higher stresses, where $t_{t}<\left\langle t_{v}, E \dot{q} .(2)\right.$ is approximated as

$$
\dot{\gamma}_{\mathrm{d}}=\mathrm{NL}^{2} \tau / \mathrm{B} \text {. }
$$

This is the viscous drag flow in which the flow stress depends linearly upon the strain rate itself. In this flow range the motion of dislocations should be not jerky but continuous.

As is seen in Eq. (2), in this model, if $U$ and $B$ are given and $\alpha=L b^{2}$ is assumed, the strain rate at which the transition occurs is determined by $\mathrm{N}$ and $\mathrm{L}$.

\section{III - THEORETICAL BACKGROUND AND EXPERIMENTAL TECHNIQUE OF THE ULTRASONIC METHOD}

Since the theoretical background and the experimental technique of the ultrasonic method for detecting dislocation behaviour under dynamic plastic deformation have been presented respectively in Ref. 6 and Refs. 4, 5 and 6 , they will be introduced briefly below.

It is believed that the mobile dislocation segments, which are contributing the plastic deformation by repeating the cutting of the forest dislocation and the jump motion are a small minority. Even during the deformation, the attenuation and the velocity change caused by the immobile dislocations may be given by GranatoLïke's theory /12/ based upon the pinned elastic string model. On the other hand, as was given by the present authors in Ref. 6 , the attenuation and the velocity change due to the mobile dislocation segments, $(\Delta \lambda)_{\mathrm{m}}$ and $(\Delta \mathrm{V})_{\mathrm{m}}$ are expressed as

$$
(\Delta \lambda)_{m}=\Omega_{m} G\left(d \dot{\gamma}_{d} / d \tau\right)_{\tau=\tau_{0}} / 2 f
$$

and

$$
(\Delta \mathrm{V} / \mathrm{V})_{\mathrm{m}}=O\left[(\Delta \lambda)_{\mathrm{m}}^{2}\right]
$$

respectively, where subscript m means the mobile dislocation, $\Omega_{\mathrm{m}}$ is an orientation factor, $G$ is the elastic modulus in shear, $\left(\mathrm{d} \dot{\gamma}_{d} / d \tau\right)_{\tau=\tau_{0}}$ is the stress derivative of the plastic strain rate at $\tau=\tau_{0}, \tau_{0}$ is the resolved shear stress due to the imposed dynamic loading, $f$ is the ultrasonic frequency and $O[]$ means the order of magnitude.

As was shown in Ref. 6 , the period of the jerky motion of the dislocation segments under the dynamic deformation, $t_{t}+t_{v}$, is considerably short compared with the period of the ultrasonic wave, $1 / \mathrm{f}$ ( $\mathrm{f}$ is of the order of $10 \mathrm{MHz}$ ), and hence the expression given by Eq. (2) can be used as $\dot{\gamma}_{d}$ in Eq. (6). When the imposed deformation is in the range of the thermal activation flow, by using Eq. (4), Eq. (6) becomes 


$$
(\Delta \lambda)_{m}=\Omega_{m} G(\alpha / k T)\left(\dot{\gamma}_{d}\right)_{\tau=\tau_{0}} / 2 f \text {. }
$$

Since $\left(\dot{\gamma}_{d}\right)_{\tau=\tau}$ is the strain rate of the imposed dynamic deformation, $(\Delta \lambda)_{m}$ depends upon the strain rate linearly. On the other hand, in the range of the viscous drag flow, substituting Eq (5) into Eq. (6):

$$
(\Delta \lambda)_{\mathrm{m}}=\Omega_{\mathrm{m}} \mathrm{GNL}^{2} / 2 \mathrm{Bf} \text {. }
$$

In this flow range, $(\Delta \lambda)_{\mathrm{m}}$ is independent of the strain rate. As is seen in $\mathrm{Eq}$. (7), the velocity change due to the mobile dislocation segments is very small and it cannot be utilised to draw information on the mobile dislocations from the ultrasonic data.

When the deformation stops, the mobile dislocation segments are immobilised, and the corresponding change in the attenuation appears. As was shown in Ref. 6 , the attenuation due to the immobilised segments is negligibly small compared with when they are moving. Hence, the attenuation due to the moving segments during the deformation can be evaluated differentially from the drop of the attenuation which appears when the deformation stops.

In the analysis of the ultrasonic data, it is assumed implicitly that the "geometric effect" of the continuous increase in the deformation during the propagation of the ultrasonic wave upon the attenuation is negligibly small compared with the dissipative attenuation due to the dislocation segments under glide motion. A quantitative verification of this assumption was given in Ref. 6 .

The details of the ultrasonic apparatus, the set-up around the specimen and the experimental technique were reported in Refs. 4, 5 and 6 . The improved ultrasonic apparatus has the resolution time of 3 usec for the repeated pulse method and 1 usec for the isolated pulse method $/ 6 /$. This time, measurements were made at temperatures up to $500 \mathrm{~K}$. For this purpose, the lithiumniobate transducers were used, and as the coupler between the transducer and the specimen an adhesive, cyanoacrylate, and a silicone adhesive were used respectively at the room and higher temperatures.

\section{IV - EXPERIMENTAL RESULTS AND DISCUSSION}

U1trasonic measurements were made for polycrystalline high purity (99.999\%) aluminium at strain rates ranging up to $8000 / \mathrm{sec}$ and at temperatures of 288,400 and $500 \mathrm{~K}$. The ultrasonic frequency was $10 \mathrm{MHz}$. The attenuation due to moving dislocation segments, $(\Delta \lambda)_{\mathrm{m}}$, which was determined differentially from the drop which appears when the deformation stops are shown in Fig. 2. Solid curves in this figure are theoretical curves calculated by using Eqs. (2) and (6) under the assumption that the mean distance between the forest dislocations, $L$, and the density of the moving dislocation segments, NL, are independent of the strain rate. The values of $\mathrm{L}$ and $\mathrm{NL}$ were so chosen that the best fit with the experimental data was obtained, but for the other physical quantities and constants known values and relationships shown below were used: that is, $G=0.26 \times 10^{12} \mathrm{dyn} / \mathrm{cm}^{2} ; \mathrm{b}=2.8 \times 10^{-8} \mathrm{~cm} ; \nu=10^{13} / \mathrm{sec} ; \mathrm{B}=$ $2.5 \times 10^{-4}, 3.16 \times 10^{-4}$ and $3.75 \times 10^{-4} \mathrm{dyn} \mathrm{sec} / \mathrm{cm}^{2}$ for 288,400 and $500 \mathrm{~K}$, respectively $113 /$ (the value at $500 \mathrm{~K}$ is extrapolated); $\Omega_{\mathrm{m}}=0.04 / 14 / ; \mathrm{U}=\mathrm{Gb}^{3} / 5 / 15 / ; \alpha=\mathrm{Lb}^{2}$ [Eq. (3) ]; $\varepsilon=\gamma / 2$. By using the approximate relation Eq. (3), the value of $\mathrm{L}$ can be determined by Eq. (8) from the experimental data of $(\Delta \lambda)_{\mathrm{m}}$ in the lower strain rate range. Thus determined value was $4.75 \times 10^{-5} \mathrm{~cm}$, and was independent of the temperature. If $\mathrm{L}$ is assumed to be independent of the strain rate $\dot{\varepsilon}$, too, it is also possible to determine NL against $\dot{\varepsilon}$. Actually, however, as is seen in Fig. 2 NL which is assumed to be independent of $\dot{\varepsilon}$ gives very good fit with the experimental data except at the high strain rate end. The deviation of the experimental data points from the constant NL curves is indicated by broken curves. On the other hand, NL depends largely upon the temperature; the values of NL determined by the fitting in 
Fig. 2 are shown in Fig. 3. The values of NL corresponding to the solid curves are $2.4,4.3$ and $6.8 \times 10^{7} / \mathrm{cm}^{2}$ for 288,400 and $500 \mathrm{~K}$, respectively. The broken curves in Fig. 3 were determined by attributing the deviation shown by broken curves in Fig. 2 to the increase in NL with increasing flow stress.

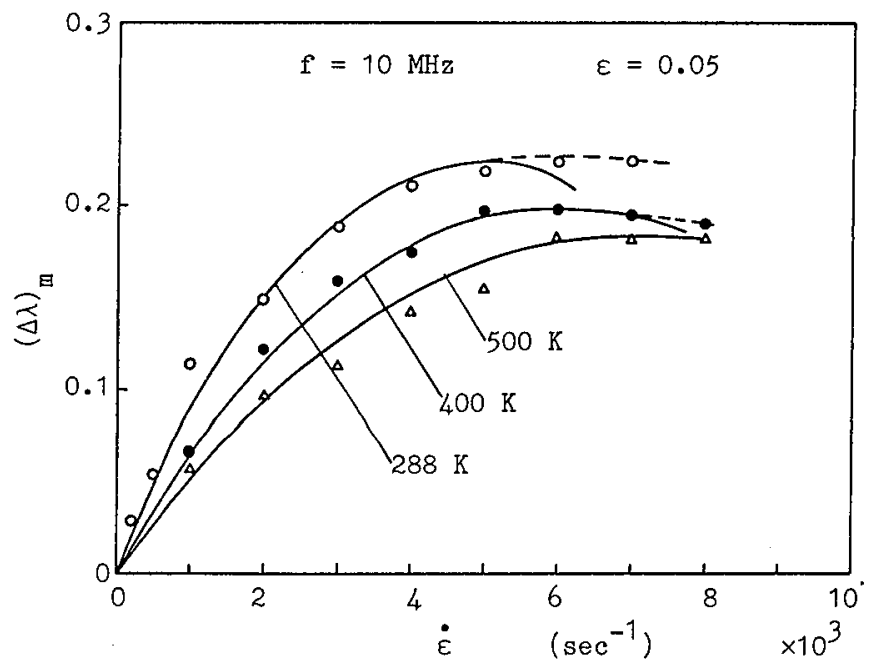

Fig. 2 - Attenuation due to mobile dislocation segments vs strain rate: - fitted curves calculated using Eq. (2); ---- deviation from culculated curves.

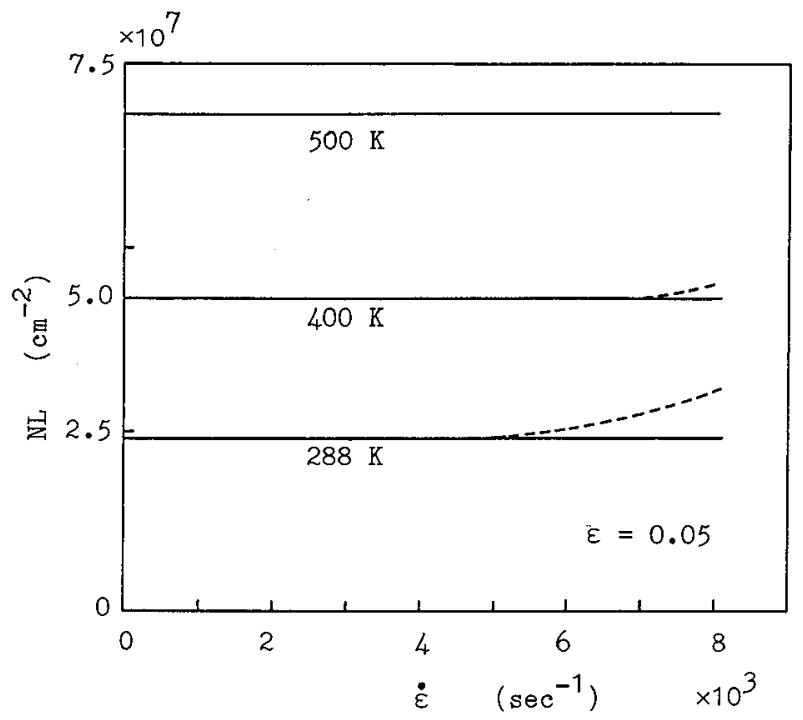

Fig. 3 - Density of mobile dislocation segments determined from ultrasonic data vs strain rate: ---- corresponds to broken curves in Fig. 2. 
Figure 4 shows the transition in the rate controlling mechanism of the dislocation motion in terms of $t_{v} /\left(t_{t}+t_{v}\right)$. The curves in this figure were calculated from Eq.

(2) by using the same numerical values and relationships as in the calculation of the curves in Fig. 2. Figure 4 indicates that the transition occurs gradually through the strain rate range from $10^{3}$ to $10^{4} / \mathrm{sec}$. The broken curves correspond to those in Figs. 2 and 3.

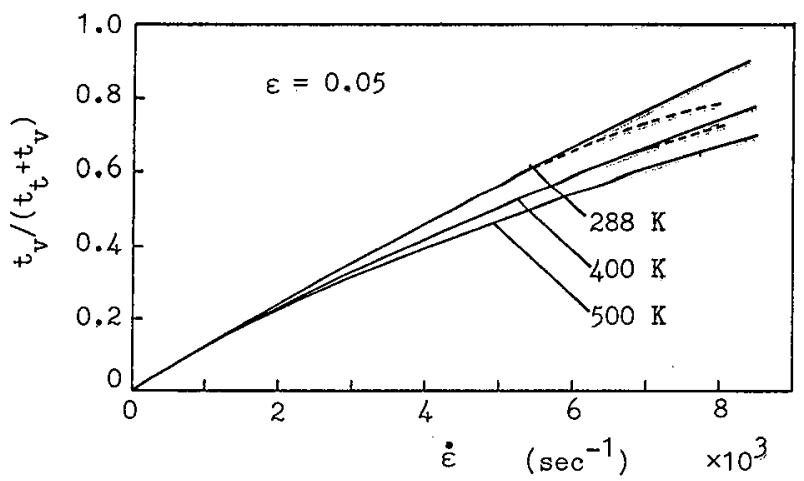

Fig. 4 - Transition in the rate controlling mechanism of dislocation segment motion in terms of $t_{v} /\left(t_{t}+t_{v}\right)$.

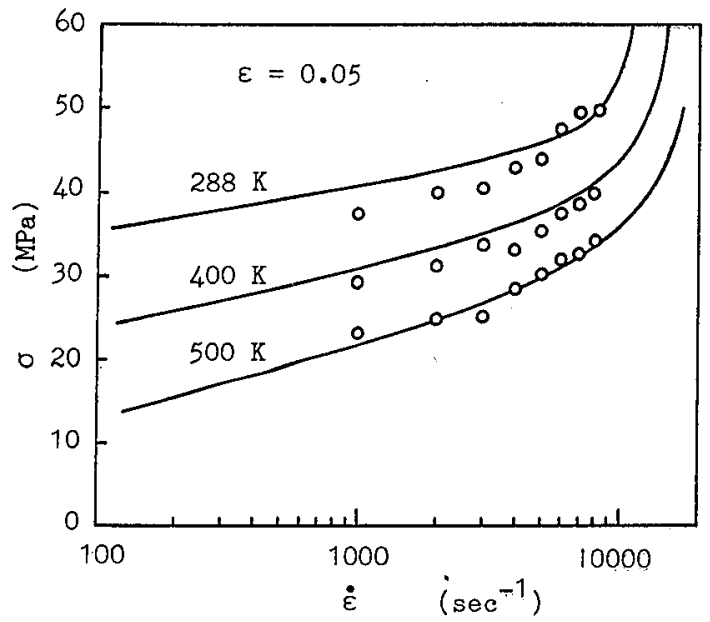

Fig. 5 - Flow stress vs strain rate: - curves calculated on the basis of ultrasonic data; O experìmental values directly measured.

In Fig. 5 the strain rate dependency of the flow stress calculated with Eq. (2) using the same numerical values and relationships as in Figs, 2 and 4 is shown. The calculated curves show fairly good agreement with the experimental values directly measured with the ultrasonic measurements. In the calculation, however, the 
Schmid factor was assumed to be 0.5 , and, furthermore, the polycrystal effect was neglected. The aboves are clearly oversimplifications even if the high symmetry of the fcc lattice is taken into account, and refinements in those geometical aspects are left for future work.

In the process of the calculation, it was of course seen that the flow stress-strain rate relationship shown by solid curves in Fig. 5 began to deviate from that of the pure thermal activation flow as $t_{v} /\left(t_{t}+t_{v}\right)$ shown in Fig. 4 increased with increasing strain rate, but as seen in Fig. 5 the sharp increase in the strain rate sensitivity of the flow stress did not appear until $t_{v} /\left(t_{t}+t_{v}\right)$ attained almost unity. As is shown in Fig. 4, the present experiment covered a range of $t_{v} /\left(t_{t}+t_{v}\right)$ up to about 0.8 , but $t_{t}$ still acted as a buffer and the drastic change in the rate sensitivity was not observed experimentally in this strain rate range. Furthermore, as is seen in Figs. 2, 3 and 4, there is a sign of the increase in the mobile dislocation density when the strain rate becomes higher, and, accordingly, the change in the rate sensitivity will become less sharp compared with the expectation under the assumption of the constant mobile dislocation density. In order to obtain experimental information on the dislocation behaviour in such a high strain rate range as the sharp change is expected to occur, further improvement in the experimental technique is required.

Excepting at the very low temperatures, the intrinsic drag given by Eq. (1) is mainly of phonon origin, and the value of B should increase with temperature. Usually, however, the experimental flow stress in the viscous flow range shows opposite temperature dependency $18,16,17 /$. This contradiction has been interpreted in terms of the temperature dependency of the density of the mobile dislocations without any direct evidence $/ 8 /$. The results of the present experiment on the mobile dislocation density shown in Fig. 3 support this interpretation. The value of $B$ at $500 \mathrm{~K}$ is about 1.5 times as large as the value at room temperature as is obtained by extrapolating the data given in Ref. 13 and used in the calculation of the theoretical curves shown in Figs. 2, 3, 4 and 5, while the corresponding ratio of NL obtained with the ultrasonic measurements is about 2.8. By taking account of the above temperature dependencies of $B$ and NL, a fairly reasonable interpretation is given by $\mathrm{Eq}$. (5).

\section{$\mathrm{V}$ - CONCLUSIONS}

In order to obtain information on the dislocation behaviour, the ultrasonic attenuation in polycrystalline high purity aluminium specimens under dynamic plastic deformation was measured over the strain rate range up to $8000 / \mathrm{sec}$ and at temperatures of 288,400 and $500 \mathrm{~K}$. Analysing the results with emphasis upon the transition in the rate controlling mechanism of the dislocation motion, the following conclusions were obtained:

1) The transition in the rate controlling mechanism of the dislocation motion from the thermal activation to the viscous drag takes place gradually over a strain rate range from about $10^{3}$ to $10^{4} / \mathrm{sec}$. However, the theoretical calculation based upon the ultrasonic data indicates that the sharp increase in the strain rate sensitivity of the flow stress begins at a little higher strain rate where the transition is almost completed. In fact, the sharp change in the rate sensitivity was not observed in the strain rate range of the present experiment.

2) The flow stress calculated with the mobile dislocation density and the mean distance between the forest dislocations determined by the ultrasonic measurements shows fairly good agreement with the flow stress directly measured. This suggests the possibility of the derivation of the constitutive equation which covers a wide range of the strain rate and temperature on the basis of the dislocation kinetics.

3) The discrepancy usually seen between the temperature dependency of the viscous drag against the dislocation motion and that of the flow stress in the viscous drag flow range can be interpreted in terms of the temperature dependency of the mobile dislocation density. 
The present experiment provided some useful knowledge concerning the transition in the rate controlling mechanism of the dislocation motion, but, in order to obtain further information especially around the strain rate where the sharp change in the strain rate sensitivity of the flow stress occurs, improvement in the experimental technique is required.

\section{ACKNOWLEDGEMENTS}

This work is a part of the project "Research on U1trasonic Spectroscopy and Its Applications to Materials Science" aided by Grant-in-Aid for Special Project Research of The Ministry of Education, Science and Culture of Japan. The authors are grateful to The Mitsubishi Foundation for their financial support.

\section{REFERENCES}

/1/ Campbel1, J. D., Mat. Sci. Eng., 12 (1973) 3.

/2/ Lindholm, U. S., Inst. Phys. Conf. Ser. No.21 (1974) 1.

/3/ Lindholm, U. S., Proc. IUTAM Symposium on High Velocity Deformation of Solids, Springer-Verlag, (1978) 26.

/4/ Shioiri, J. and Satoh, K., Inst. Phys. Conf. Ser. No.21 (1974) 154.

/5/ Shioiri, J. and Satoh, K., ibid. No.47 (1980) 121.

/6/ Shioiri, J. and Satoh, K., ibid. No.70 (1984) 89.

/7/ Shioiri, J., Satoh, K. and Nishimura, K., Proc. IUTAM Symposium on High Velocity Deformation of Solids, Springer-Verlag, (1978) 50.

/8/ Kumar, A. and Kumble, R. G., J. Appl. Phys. 40 (1969) 3475.

/9/ Follansbee, P. S., Regazzoni, G. and Kocks, U. F., Inst. Phys. Conf. Ser. No.70 (1984) 71 .

/10/ Vreeland, T. Jr., Dislocation Dynamics, McGraw-Hi11, (1968) 529.

/11/ Seeger, A., Dislocations and Mechanical Properties of Crystals, Wiley, (1957)

243.

/12/ Granato, A. and Lücke, K., J. Appl. Phys. 27 (1956) 583 and 789.

/13/ Gorman, J. A., Wood, D. S. and Vreeland, T. Jr., J. Appl. Phys. 40 (1969) 833. /14/ Hikata, A., True11, R., Granato, A., Chick, B. and Lücke, K., J. Appl. Phys. 27 (1956) 396.

T15/ Ashby, M. F. and Frost, H. J., Constitutive Equations in Plasticity, MIT Press, (1975) 117 .

/16/ Ferguson, W. G., Kumar, A. and Dorn, J. E., J. Appl. Phys. 38 (1967) 1836.

/17/ Kumar, A., Hauser, F. E. and Dorn, J. E., Acta Met., 16 (1968) 1189. 